Research Article

\title{
Structural Health Monitoring of the Scaffolding Dismantling Process of a Long-Span Steel Box Girder Viaduct Based on BOTDA Technology
}

\author{
Yong Ding, Feng Xiao $(\mathbb{D}$, Weiwei Zhu, and Tao Xia \\ Department of Civil Engineering, Nanjing University of Science and Technology, Nanjing, Jiangsu 210094, China \\ Correspondence should be addressed to Feng Xiao; xiaofeng@njust.edu.cn
}

Received 23 April 2019; Revised 16 July 2019; Accepted 3 August 2019; Published 4 September 2019

Academic Editor: Carlo Rainieri

Copyright @ 2019 Yong Ding et al. This is an open access article distributed under the Creative Commons Attribution License, which permits unrestricted use, distribution, and reproduction in any medium, provided the original work is properly cited.

\begin{abstract}
In this study, a distributed optical fiber sensing technique based on Brillouin optical time-domain analysis (BOTDA) is used to construct a complete bridge health monitoring system by continuously laying distributed sensing fiber lines in a steel box girder. The bridge scaffolding dismantling process is monitored to study the variation of the strain distribution. Additionally, a bridge finite element model is built to simulate the bridge scaffolding removed condition, and the strain distribution of the long-span steel box girder viaduct after scaffolding dismantling is compared with the measured values. This study provides a reference for monitoring the scaffolding dismantling process based on BOTDA technology.
\end{abstract}

\section{Introduction}

With the rapid development of the transportation industry, long-span bridges have been built in large numbers. As key components of the transportation network, the bridge safety, durability, and applicability are always of concern. During the construction and operation of bridges, various types of damage can occur to the bridge structure, which is subjected to various loads, the natural environment, and material degradation $[1,2]$. A bridge health monitoring system is necessary to monitor the safe operation of bridges [3-6] and take the corresponding technical measures in a timely fashion for the maintenance of damaged bridges.

In addition to safety monitoring during the service period, the structure and deformation of the bridge should be monitored during construction [7-11]. Because the bridge body is under severe stress changes during construction [12], problems such as weld fracture and large deformations are likely to occur during this period [7]. In addition to considering the performance of the bridge itself, the safety of the structure when removing the support frame should be considered $[8,13]$, since accidental collapse may occur during this period. Useful information can be obtained to minimize the construction uncertainty of bridge monitoring during construction [9-11]. A reliable and stable warning system is required to provide the time for remediation work on bridges before a disaster strikes. Longterm monitoring can provide accurate and reliable information about the nature and extent of bridge degradation, so bridge managers can make the correct decisions [8]. Therefore, it is also necessary to monitor the safety of the bridge body during construction.

The subject of this research project is the steel box girder across the Huangxiaohe section of the Huangpu StreetJinqiao Avenue Expressway Project in Wuhan, China. The distributed optical fiber sensing technology is used to monitor the deformation of the bridge during the dismantling process. During the assembly of the bridge box girder, to stabilize the bridge body, the bottom of the bridge is supported by a steel frame. After the bridge assembly work is completed, and the bridge body is basically stable, the scaffolding is removed. When the scaffolding is removed, the bridge body has no bottom support, so large deformations in the axial and vertical directions can occur, the bridge may be damaged, and occasional accidents may occur. Therefore, the bridge behavior must be monitored during this period. 
This study used Brillouin optical time-domain analysis (BOTDA) technology to monitor the whole length of the steel box girder strain during the dismantling process. A bridge finite element model was built to simulate the bridge scaffolding removed condition, and the results were compared with the measured values to study the correlation for each measurement line.

\section{BOTDA Technology}

This research project utilizes a distributed optical fiber system based on BOTDA [14]. This system is waterproof, corrosion-resistant, and durable. The sensing element is compact, lightweight, wide in measurement range, and easy to install [15]. The optical fiber is both a sensing element and a signal transmission medium and can realize remote distributed monitoring. At present, Brillouin optical timedomain reflectometer (BOTDR) and BOTDA are most commonly used in long-distance distributed temperature and strain measurements [16]. The BOTDR-based distributed optical fiber sensor detects self-emitted Brillouinscattered light, but due to the weak optical power, it is difficult to achieve high-precision, long-distance distributed sensing [15].

The BOTDA-based distributed optical fiber sensor utilizes the stimulated Brillouin scattering between direct-current (DC) detection light and pulsed pumping light to amplify the detection light through the stimulated Brillouin effect, which achieves characteristics, such as high-strength received signals, high measurement accuracy, and wide dynamic range [17]. Kwon [18] measured the change in distributed temperature on the building under construction by fiber optic sensors. Glisic et al. [19] monitored the integrity of old steel bridge using fiber optic distributed sensors based on Brillouin scattering. Mufti et al. [20] identified cracks of steel girders using BOTDA. Bernini et al. [21] measured the distributed strain of the bridge using a time-domain Brillouin sensing system. Zeni et al. [22] used Brillouin optical time-domain analysis for geotechnical monitoring. However, limited research has applied Brillouin optical time-domain analysis in the dismantling process of bridge supports. This technology provides high-precision temperature and strain measurements with submeter spatial resolution on the long sensing length $[16,17]$. Another advantage of BOTDA technology is that the same optical fibers can be reused many times. Therefore, the strain profile can be periodically obtained to allow the monitoring of the health of the structure under investigation throughout their service life [21]. For large-scale building structures, this technology is easily embedded and sensitive, and the distributed information of the structure can be simultaneously obtained [23].

The basic principle of BOTDA technology is that the laser emitters at both ends of the fiber inject a pulsed light and a continuous beam of light into the optical fiber. When the frequency difference between the pulsed light and the continuous light is equal to the Brillouin frequency shift of a certain interval in the fiber, there is a stimulated Brillouin amplification effect, and energy transfer occurs between the two beams [14]. According to the relationship between the fiber Brillouin frequency shift and the strain and temperature of the fiber, the frequencies of the two lasers are continuously adjusted, and the continuous optical power coupled from one end of the fiber is monitored to determine the frequency at the maximum energy transfer in each region of the fiber [17]. The frequency shift can be input into equation (1) to obtain the required strain or temperature information:

$$
\Delta v B(z)=C_{1} \cdot \Delta \varepsilon(z)+C_{2} \cdot \Delta T(z),
$$

where $\Delta v B(z)$ is the Brillouin optical frequency shift, $\Delta \mathcal{E}(z)$ is the strain change at the sensing fiber, $\Delta T(z)$ is the temperature change at the sensing fiber, and $C_{1}$ and $C_{2}$ are the strain coefficient and temperature coefficient of the Brillouin frequency shift of the fiber, respectively.

Coefficients $C_{1}$ and $C_{2}$ in the equation are not fixed and vary with the fiber. In general, these values need to be calibrated before use.

\section{Long-Span Steel Box Girder Bridge Health Monitoring}

The steel box girder (Figure 1) of the Huangpu StreetJinqiao Avenue Expressway Project in Wuhan is a long-span steel box girder viaduct. A 3-span continuous steel box girder structure is used, and the lengths of the three spans are 100 meters, 150 meters, and 100 meters. In light of the safety problems that may occur during the construction and operation of the bridge, the structural health of the bridge during the construction process and the trial operation phase is monitored.

The monitoring system consists of three parts: the sensing layer, the network layer, and the application layer [4]. The sensing layer is composed of distributed optical fibers inside the bridge body, and the measured deformation data of the bridge are obtained using the laid fiber [15]. Then, the measured bridge data are transmitted to the network layer and further analyzed and processed. The results of the final analysis are transmitted to the application layer, i.e., the deformation information is transformed into a report or graphical form that is easy to view and analyze, and the bridge is further analyzed [17].

Six distributed sensing fiber lines are placed inside the steel box girder. As shown in Figure 2, 1-4 are strainsensing fiber lines, and 5-6 are temperature-sensing fiber lines; the structure of the optical fiber is shown in Figure 3. The optical fiber line is placed in the groove of the T-rib on the bottom surface of the bridge and fixed by a mixture of epoxy resin and curing agent at a certain ratio (Figure 4), and the data are collected by a linked optical fiber demodulator. This research project uses the Omnisen DiTeSt fiber demodulator.

The changes in the Brillouin frequency shift obtained from the temperature-sensing lines are subtracted from the sensor network monitoring data to eliminate the effect of temperature changes on the data. The bridge health 


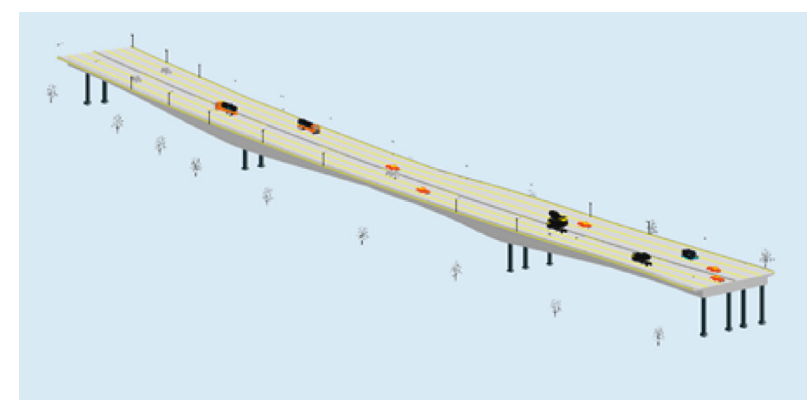

FIGURE 1: Steel box girder bridge.

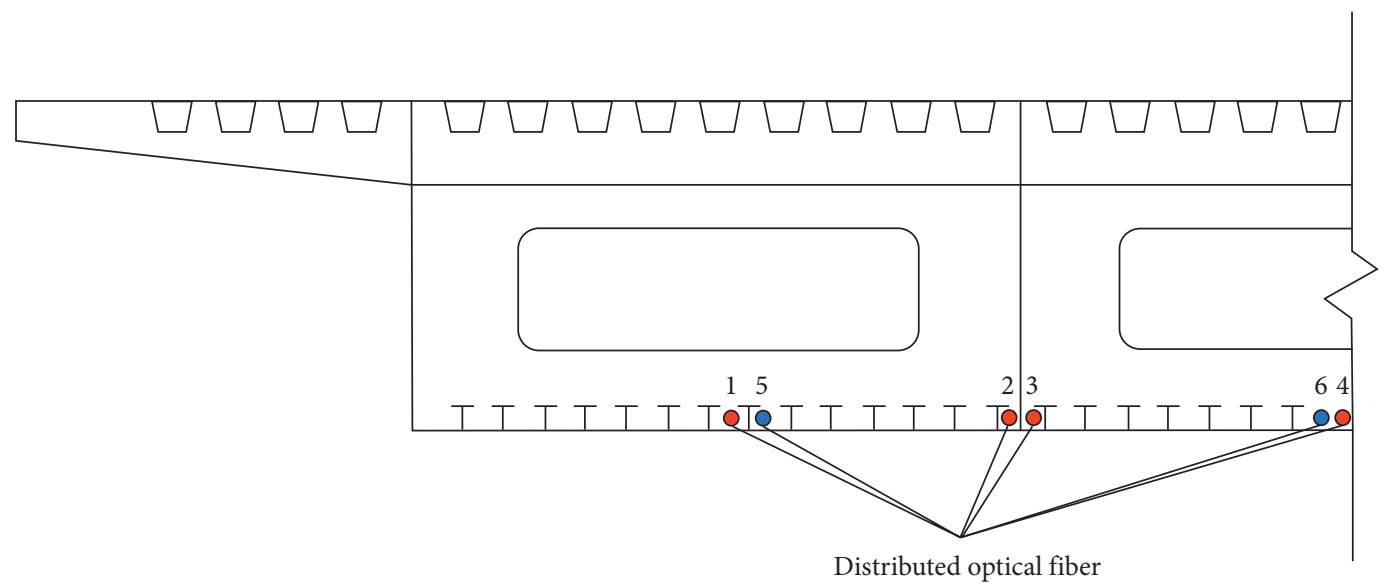

Figure 2: Schematic diagram of the locations of the fibers.

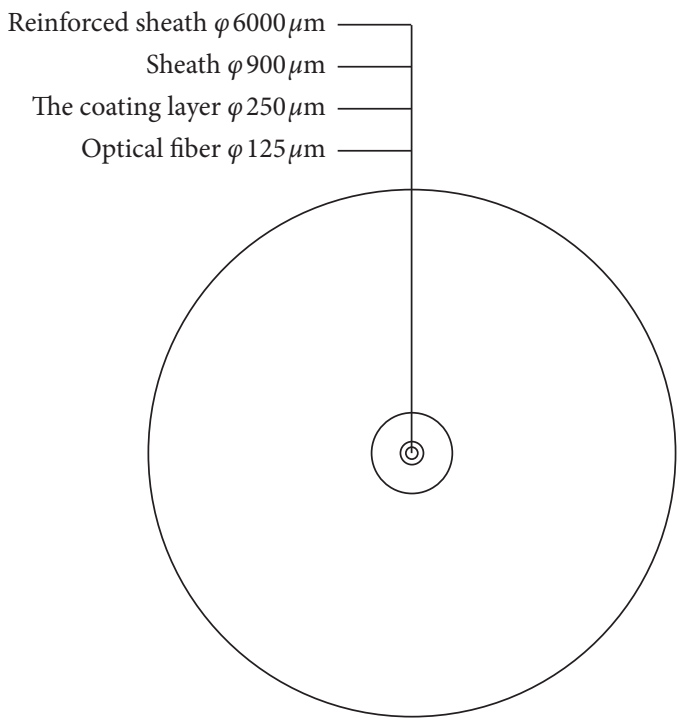

Figure 3: Structures of the optical fiber.

monitoring system can achieve distributed strain measurements on the steel box girder with a sampling interval of $0.1 \mathrm{~m}$ and a strain measurement accuracy of 20 microstrains [17].

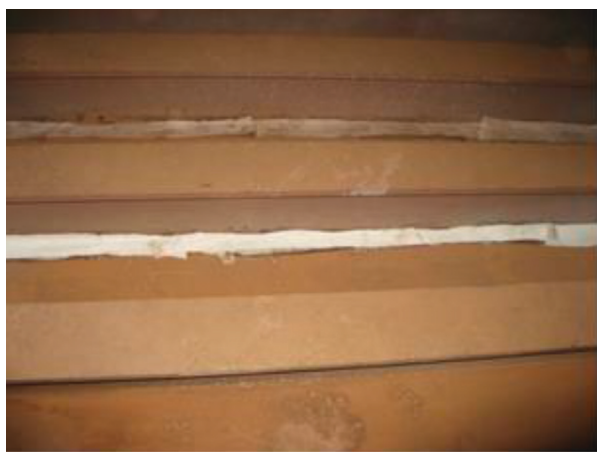

Figure 4: Distributed sensing fiber line on the bottom plate of the steel box girder.

\section{Scaffolding Dismantling Process and Monitoring}

This project is intended to study the deformation of the whole bridge during the scaffolding dismantling process, where the scaffolding under the steel box girder bridge is removed, and the weight of the bridge is supported by the piers. Scaffolding dismantling begins at the middle position of the $150 \mathrm{~m}$ span of the bridge body; two construction teams simultaneously perform the scaffolding dismantling work in the north and 


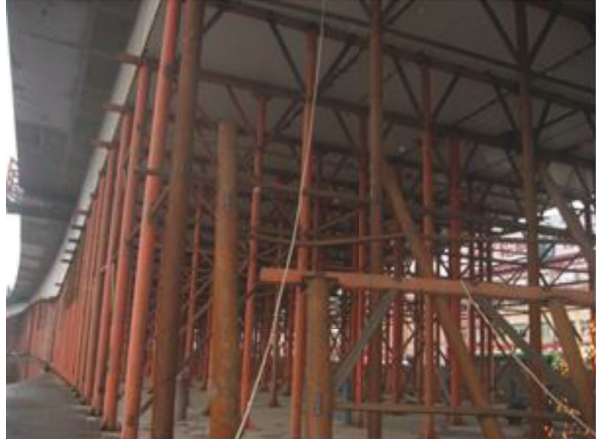

(a)

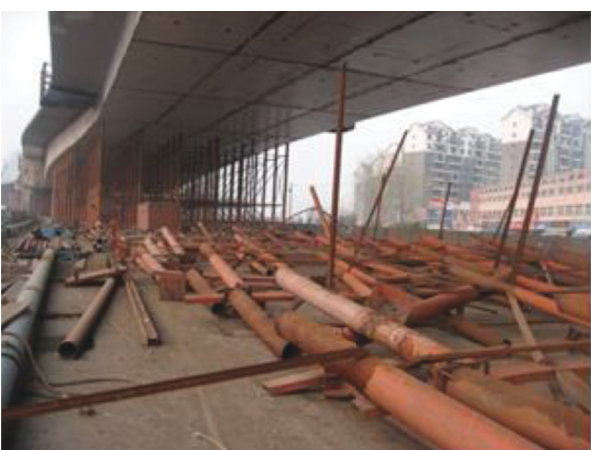

(b)

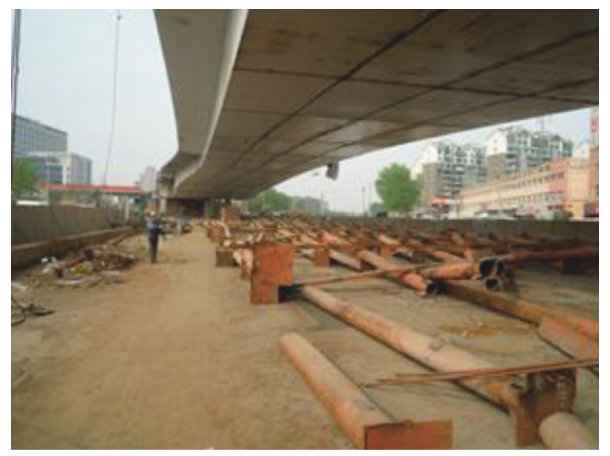

(c)

FIgURe 5: Scaffolding dismantling process.

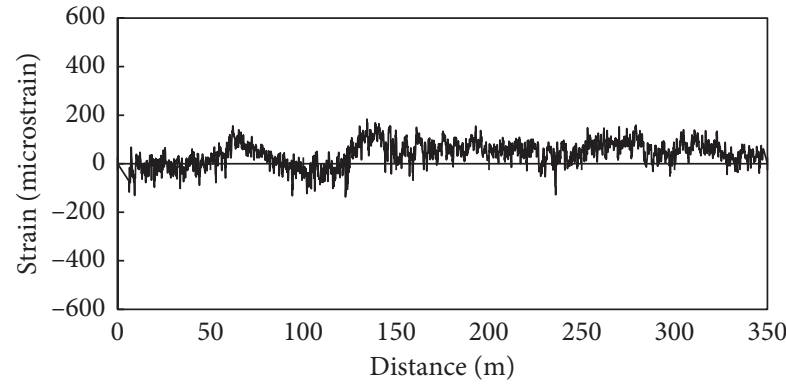

(a)

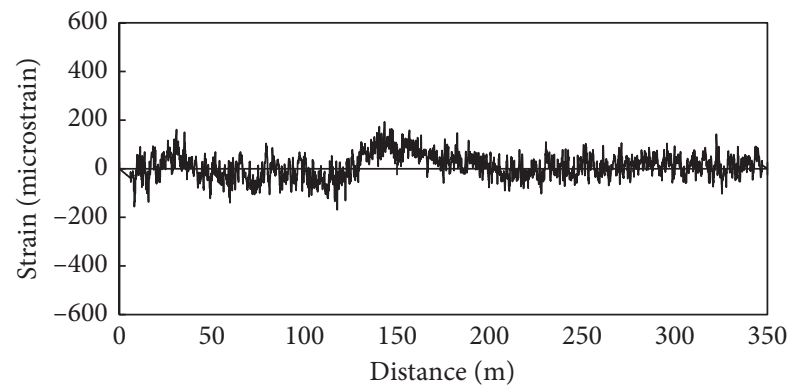

(c)

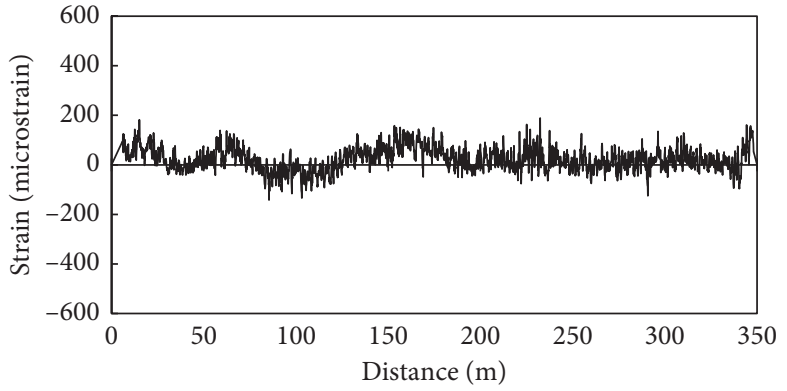

(b)

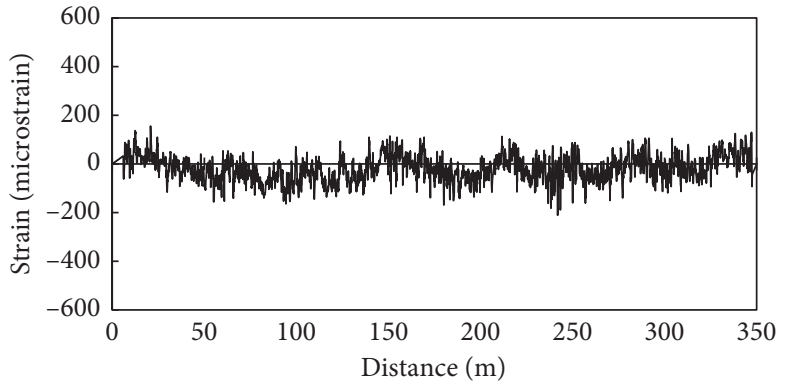

(d)

Figure 6: Strain diagrams of lines 1-4 in the early stage of the scaffolding removal. (a) Line 1. (b) Line 2. (c) Line 3 . (d) Line 4.

south directions. Through the coordinated operation on both sides, the scaffolding is eventually removed (Figure 5). When the scaffolding is removed, the bridge deformation is monitored by a real-time data monitoring system. Figure 6 shows the strain diagrams in the early stage of the scaffolding removal, where 0-350 meters represents the south-to-north direction of the bridge body.

In the early stage of scaffolding dismantling, the force structure of the bridge body greatly changes, and a large strain is generated. During the process of scaffolding dismantling, 


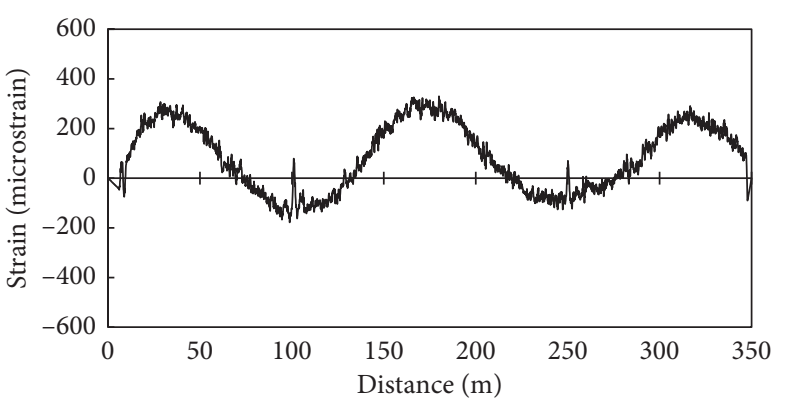

(a)

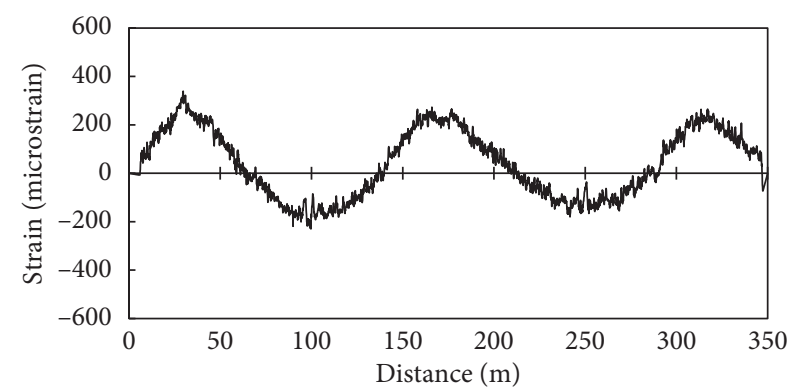

(c)

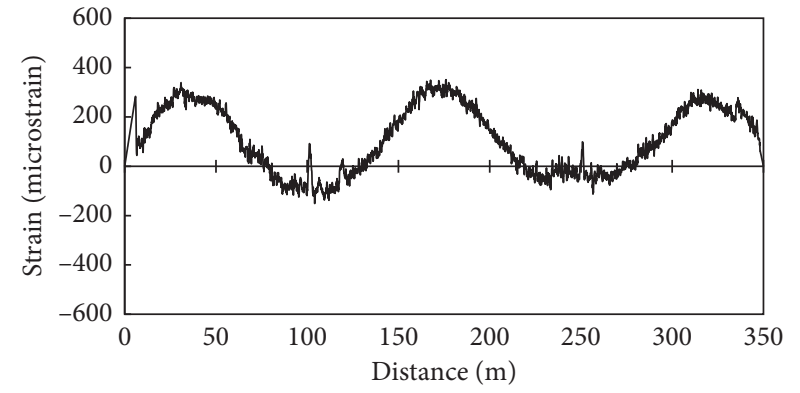

(b)

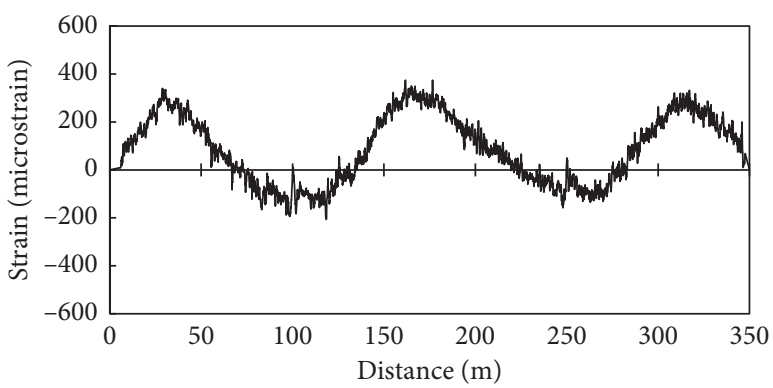

(d)

FIGURE 7: Strain diagrams of lines 1-4 after dismantling the scaffolding. (a) Line 1. (b) Line 2. (c) Line 3. (d) Line 4.

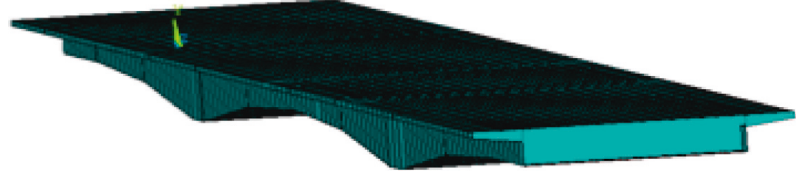

Figure 8: Bridge finite element model.

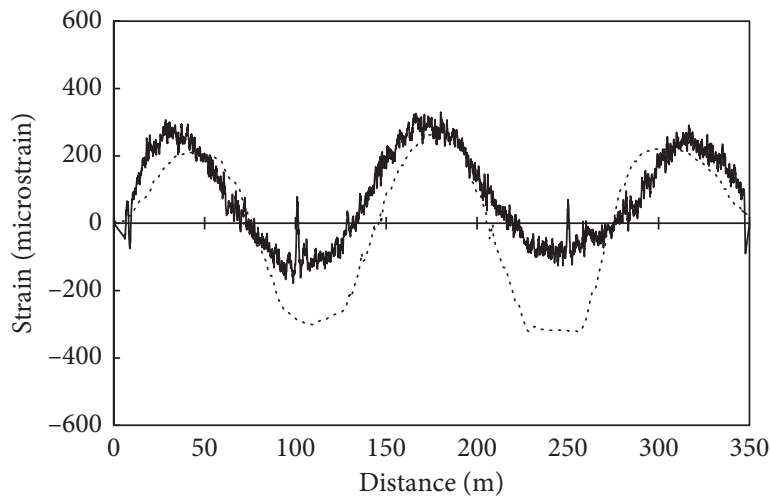

Field measurement Model analysis

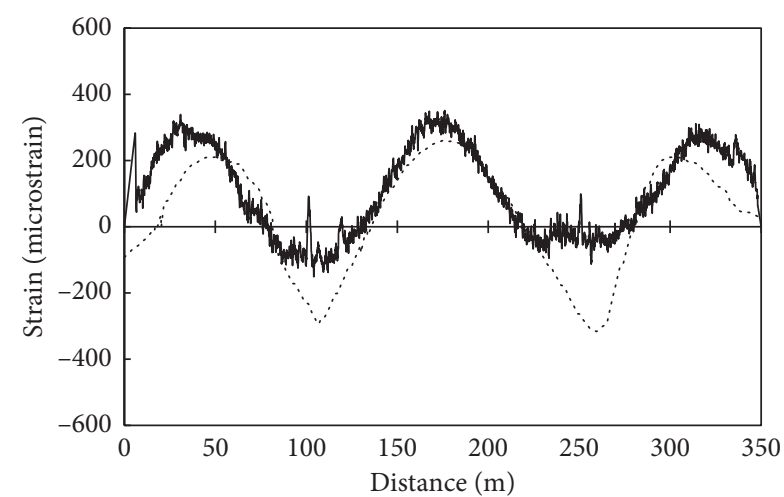

— Field measurement Model analysis

(a)

(b)

Figure 9: Continued. 


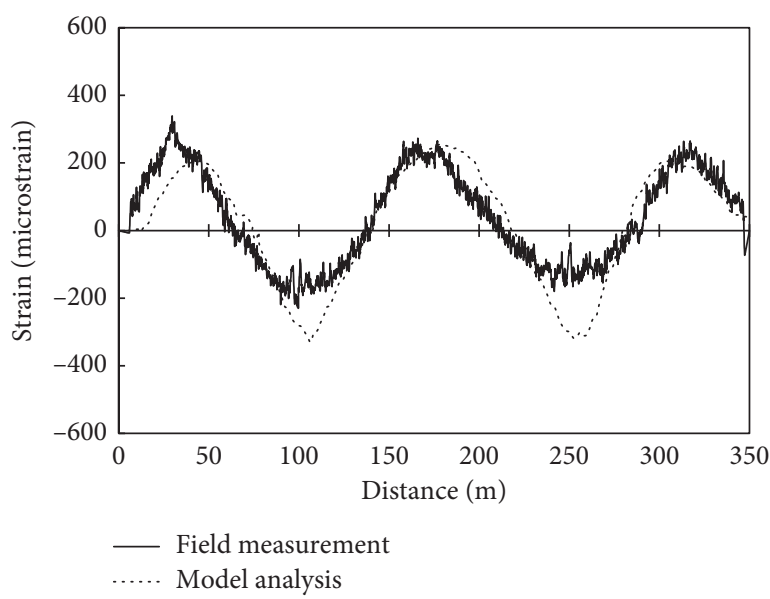

(c)

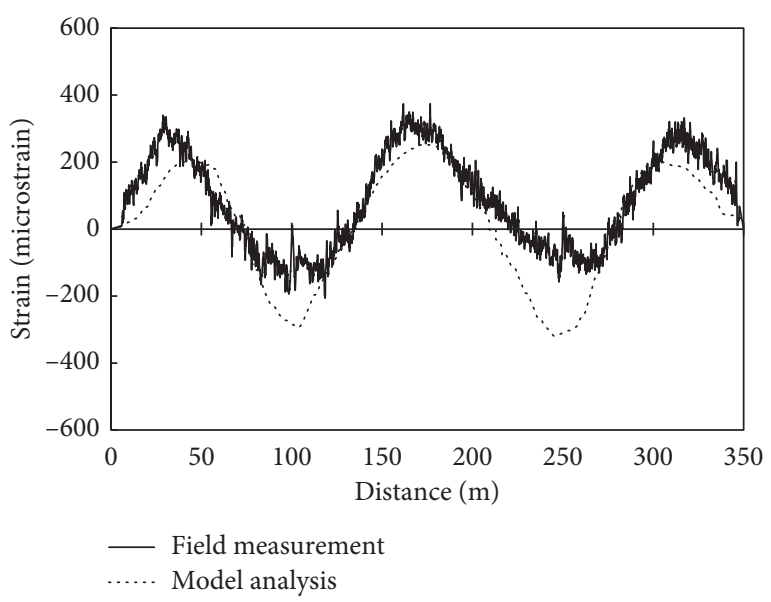

(d)

FIgURE 9: Comparison of the measured and simulated strains of lines 1-4. (a) Line 1. (b) Line 2. (c) Line 3. (d) Line 4.

the stresses in different cross sections of the bridge vary due to the uneven stress distribution. In total, four strain-sensing fiber lines are laid during the implementation of the project, so it is possible to analyze and compare the force changes at different positions of the same cross section. Five days after the bridge scaffolding is removed, the bridge body is basically stable, and the stress distribution is fairly uniform. At this time, the differences in strain of the four lines measured on the same day are small. Figure 7 shows the strain diagrams of line 1 to line 4 after the scaffolding has been removed, and the result reveals that the differences in strain due to different line positions are not large.

\section{Deformation Simulation of the Bridge Body after the Scaffolding Dismantling}

To understand the deformation pattern of a long-span variable-cross-section steel box girder bridge under stress, a bridge model is built, and the shell element is adopted in the model (Figure 8). When the scaffolding is removed, the constraint condition of the bridge is only a vertical constraint at the pier, i.e., the vertical constraints are set at the north and south ends of the bridge and $100 \mathrm{~m}$ from the north and south bridge spans. A uniform gravity is applied to the established model, and the results are calculated. Figure 9 shows the simulated strain diagrams based on the numerical calculation at the positions of lines 1-4, and the field measurement result after the scaffolding removal is added in Figure 9 for comparison.

Pearson correlation coefficient between the field measurement and the model analysis data is calculated. The correlation coefficients of lines $1-4$ are $0.88,0.83,0.89$ and 0.89 , respectively. The field measured and analyzed strain of lines 1-4 has a very strong correlation. The measured data of the negative strain are slightly larger than the software simulation values because the software calculation conditions are ideal, but the welding stress and uneven distribution of stress in the bridge during the field construction can affect the strain values. In the finite element model, the constraints added at the pier are vertical constraints, and there is no constraint in the radial direction of the bridge. However, although the bridge support has no fixed constraint in the radial direction, due to the existence of the frictional force, there are certain constraints in the radial direction.

\section{Conclusions}

The monitoring of the bridge during the scaffolding dismantling process can reveal the strain redistribution. In this study, the distributed sensing fiber lines were installed in the steel box girder, and each line had a length of more than $350 \mathrm{~m}$. The on-line monitoring of the bridge strain during the scaffolding dismantling process was carried out. The data with an interval of $0.1 \mathrm{~m}$ recorded the strain distribution of the whole length of the steel box girder. A bridge finite element model was built to simulate the scaffolding removed condition, and the strain distribution results were compared with the measured data to study the correlation for each measurement line. This study revealed the box girder strain redistribution caused by the scaffolding dismantling process. In future studies, the bridge finite model will be updated based on results obtained in the field, and the safety performance of the bridge will be comprehensively evaluated.

\section{Data Availability}

The data used to support the findings of this study are available from the corresponding author upon request.

\section{Conflicts of Interest}

The authors declare that they have no conflicts of interest.

\section{Acknowledgments}

This work was supported by Nanjing University of Science and Technology, Start-Up, grant number: AE89991. 


\section{References}

[1] G. C. Sih, X. S. Tang, Z. X. Li, A. Q. Li, and K. K. Tang, "Fatigue crack growth behavior of cables and steel wires for the cablestayed portion of Runyang bridge: disproportionate loosening and/or tightening of cables," Theoretical and Applied Fracture Mechanics, vol. 49, no. 1, pp. 1-25, 2008.

[2] B. Chapuis, "Introduction to structural health monitoring," in Sensors, Algorithms and Applications for Structural Health Monitoring, B. Chapuis and E. Sjerve, Eds., pp. 1-11, Springer International Publishing, Basel, Switzerland, 2015.

[3] E. Mesquita, P. Antunes, F. Coelho, P. André, A. Arêde, and H. Varum, "Global overview on advances in structural health monitoring platforms," Journal of Civil Structural Health Monitoring, vol. 6, no. 3, pp. 461-475, 2016.

[4] C.-C. Comisu, N. Taranu, G. Boaca, and M.-C. Scutaru, "Structural health monitoring system of bridges," Procedia Engineering, vol. 199, pp. 2054-2059, 2017.

[5] M. Modare and N. Waksmanski, "Overview of structural health monitoring for steel bridges," Practice Periodical on Structural Design and Construction, vol. 18, no. 3, pp. 187-191, 2013.

[6] F. Xiao, J. L. Hulsey, and R. Balasubramanian, "Fiber optic health monitoring and temperature behavior of bridge in cold region," Structural Control and Health Monitoring, vol. 24, no. 11, pp. 1-11, 2017.

[7] D. Inaudi, A. Rufenacht, B. von Arx, H. P. Noher, S. Vurpillot, and B. Glisic, "Monitoring of a concrete arch bridge during construction," in Proceedings of SPIE-The International Society for Optical Engineering, vol. 4696, pp. 146-153, San Diego, CA, USA, March 2002.

[8] Y. B. Lin, C. L. Pan, Y. H. Kuo, K. C. Chang, and J. C. Chern, "Online monitoring of highway bridge construction using fiber Bragg grating sensors," Smart Materials and Structures, vol. 14, no. 5, pp. 1075-1082, 2005.

[9] H.-H. Choi, S.-Y. Lee, I.-Y. Choi, H.-N. Cho, and S. Mahadevan, "Reliability-based failure cause assessment of collapsed bridge during construction," Reliability Engineering \& System Safety, vol. 91, no. 6, pp. 674-688, 2006.

[10] A. Dalvi, M. Norouzi, V. Hunt, and A. Helmicki, "Structural health monitoring system of Ironton-Russell bridge during substructure construction," in Proceedings of the Smart Structures and Materials + Nondestructive Evaluation and Health Monitoring (SPIE 9805), Las Vegas, NV, USA, March 2016.

[11] J. R. Casas and A. C. Aparicio, "Monitoring of the Alamillo cable-stayed bridge during construction," Experimental Mechanics, vol. 38, no. 1, pp. 24-28, 1998.

[12] F. Matta, F. Bastianini, N. Galati, P. Casadei, and A. Nanni, "Measurement of distributed strain in steel bridge: validation through diagnostic load test," Doctoral dissertations, Missouri University of Science and Technology, Rolla, MO, USA, 2007.

[13] L. Jiang and R. Gao, "Deformation monitoring during removal of the supporting of T-type rigid frame bridge constructed by rotation method," Procedia Engineering, vol. 4, pp. 355-360, 2010.

[14] M. Tateda and T. Horiguchi, "BOTDA-nondestructive measurement of single- mode optical fiber attenuation characteristics using Brillouin interaction theory," Journal of Lightwave Technology, vol. 7, no. 8, pp. 1170-1176, 1989.

[15] L. Thévenaz, "Brillouin distributed time-domain sensing in optical fibers: state of the art and perspectives," Frontiers of Optoelectronics in China, vol. 3, no. 1, pp. 13-21, 2010.
[16] T. Horiguchi, T. Kurashima, and M. Tateda, "A technique to measure distributed strain in optical fibers," IEEE Photonics Technology Letters, vol. 2, no. 5, pp. 352-354, 1990.

[17] X. Bao and L. Chen, "Recent progress in optical fiber sensors based on Brillouin scattering at university of Ottawa," Photonic Sensors, vol. 1, no. 2, pp. 102-117, 2011.

[18] I.-B. Kwon, "Distributed measurements of structures by fiber optic sensors," KSCE Journal of Civil Engineering, vol. 7, no. 6, pp. 659-666, 2003.

[19] B. Glisic, D. Posenato, and D. Inaudi, "Integrity monitoring of old steel bridge using fiber optic distributed sensors based on Brillouin scattering," in Proceedings of the 3rd International Conference on Structural Health Monitoring of Intelligent Infrastructure-SHMII-3, San Diego, CA, USA, April 2007.

[20] A. Mufti, D. Thomson, D. Inaudi, H. M. Vogel, and D. McMahon, "Crack detection of steel girders using Brillouin optical time domain analysis," Journal of Civil Structural Health Monitoring, vol. 1, no. 3-4, pp. 61-68, 2011.

[21] R. Bernini, L. Amato, A. Minardo, and L. Zeni, "Bridge monitoring by distributed strain measurement using a timedomain Brillouin sensing system," Lecture Notes in Electrical Engineering, vol. 91, pp. 439-442, 2011.

[22] L. Zeni, L. Picarelli, B. Avolio et al., "Brillouin optical timedomain analysis for geotechnical monitoring," Journal of Rock Mechanics and Geotechnical Engineering, vol. 7, no. 4, pp. 458-462, 2015.

[23] I.-B. Kwon, M. Malekzadeh, Q. Ma et al., "Fiber optic sensor installation for monitoring of 4 span model bridge in UCF," Rotating Machinery, Structural Health Monitoring, Shock and Vibration, vol. 5, pp. 383-388, 2011. 


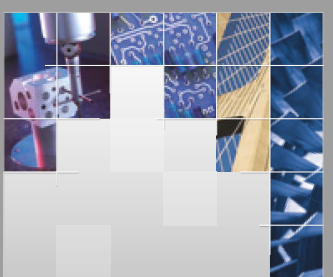

\section{Enfincering}
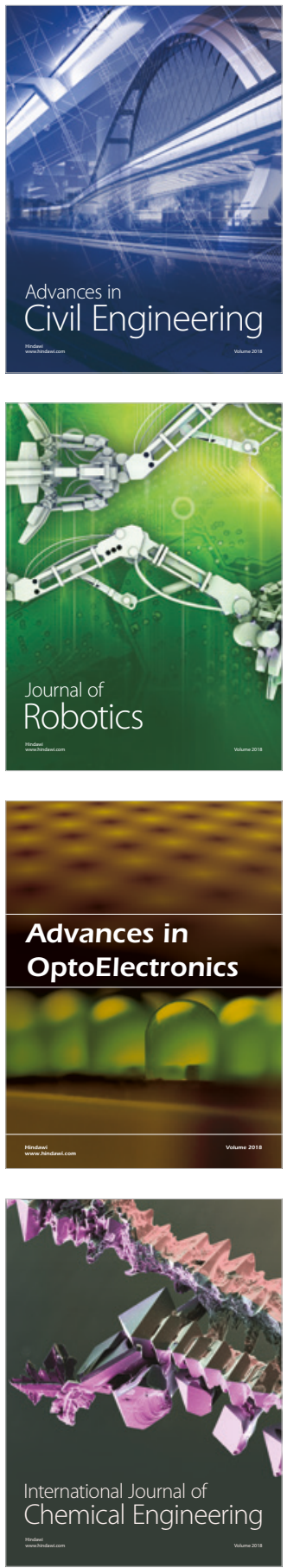

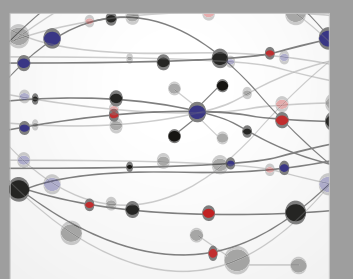

\section{Rotating \\ Machinery}

The Scientific World Journal

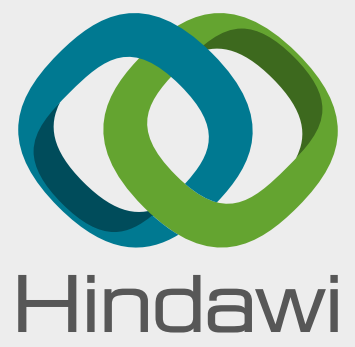

Submit your manuscripts at

www.hindawi.com
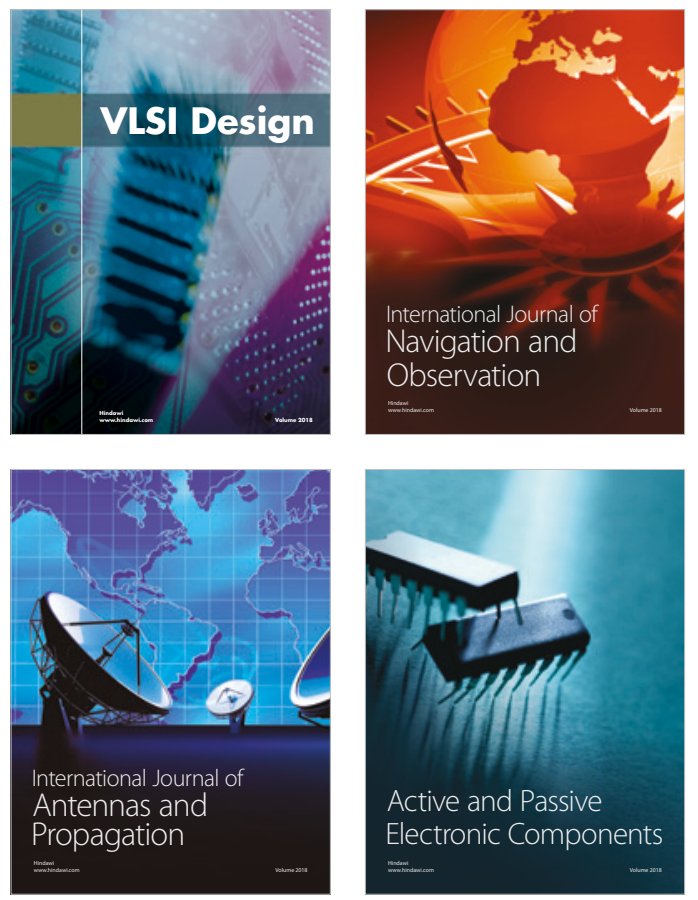
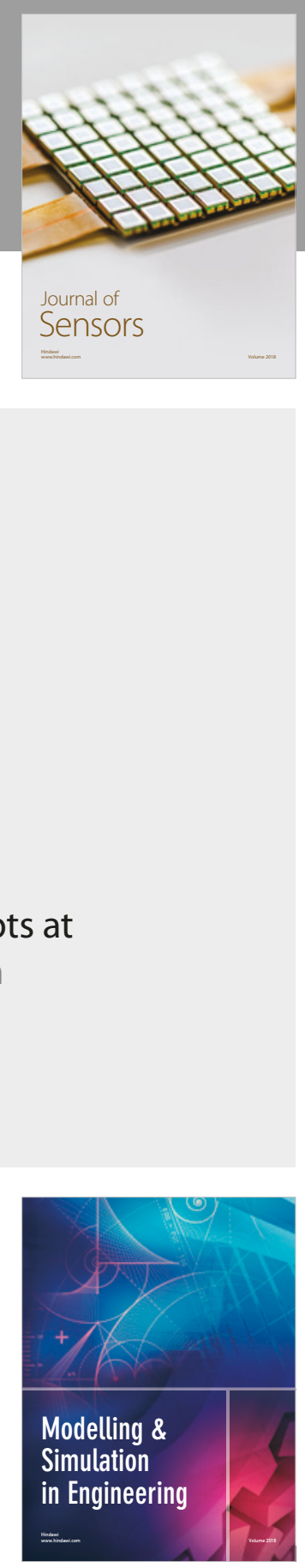

\section{Advances \\ Multimedia}
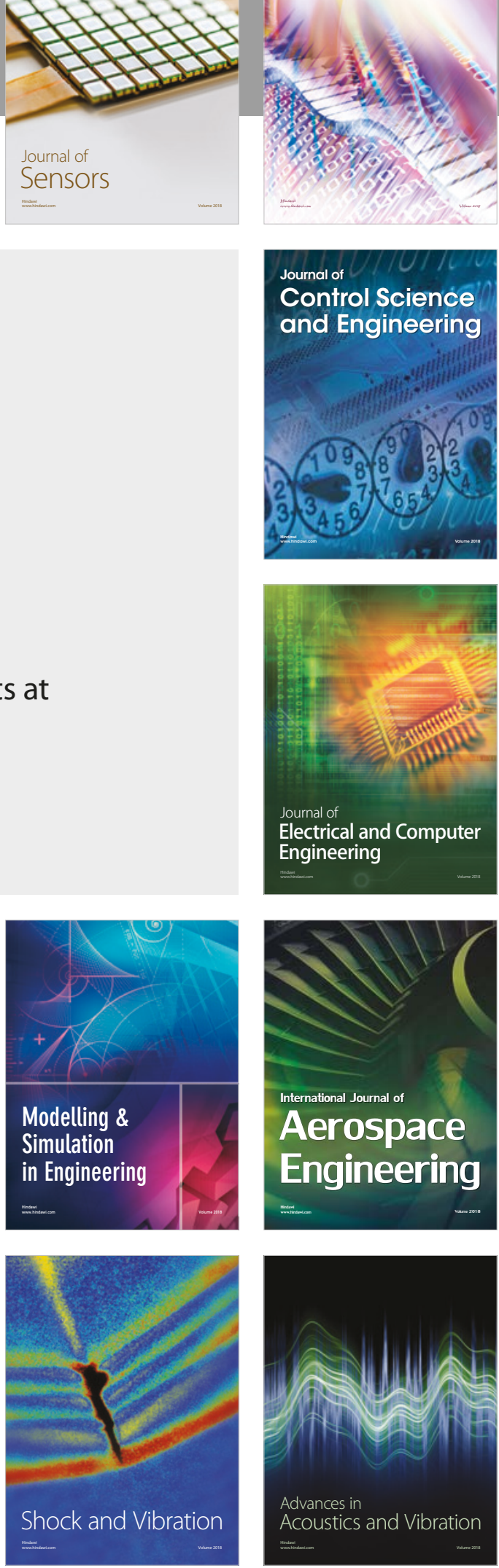